\title{
Convergências teóricas e dados empíricos no estudo do transnacionalismo imigrante
}

Theoretical Convergencies and Empirical Evidence in the Study of Immigrant

Transnationalism

L'étude du transnationalisme migratoire

\section{Alejandro Portes}

Tradutor. João Paulo Moreira

\section{OpenEdition}

\section{Journals}

\section{Edição electrónica}

URL: http://journals.openedition.org/rccs/1339

DOI: $10.4000 /$ rccs. 1339

ISSN: 2182-7435

\section{Editora}

Centro de Estudos Sociais da Universidade de Coimbra

\section{Edição impressa}

Data de publição: 1 Outubro 2004

Paginação: 73-93

ISSN: 0254-1106

Refêrencia eletrónica

Alejandro Portes, " Convergências teóricas e dados empíricos no estudo do transnacionalismo imigrante », Revista Crítica de Ciências Sociais [Online], 69 | 2004, colocado online no dia 01 outubro 2012, criado a 19 abril 2019. URL : http://journals.openedition.org/rccs/1339 ; DOI : 10.4000/ rccs. 1339 


\section{ALEJANDRO PORTES}

\section{Convergências teóricas e dados empíricos no estudo do transnacionalismo imigrante}

Sintetizam-se alguns dos pontos empíricos e conceptuais em relação aos quais os estudos sobre o transnacionalismo, até há pouco envolvidos em litígio, atingiram uma certa forma de consenso. Esses pontos são indicadores de progresso, na medida em que a evidência dos dados e a reflexão subsequente sobre eles levaram investigadores com perspectivas muito diferentes a porem-se de acordo sobre a consistência de certos argumentos e a fragilidade de outros. Apresentam-se cinco conclusões que parece terem-se tornado consensuais entre os especialistas desta área.

Proponho-me fazer o contrário daquilo que geralmente se espera de uma conclusão: em vez de apresentar um conjunto de reflexões teóricas sobre o material empírico, vou proceder a uma apresentação abreviada dos resultados decorrentes dos inquéritos do Projecto Comparado sobre o Empreendedorismo Imigrante (Comparative Immigrant Entrepreneurship Project - CIEP), recentemente concluídos. Antes disso, contudo, seria útil resumir alguns dos pontos empíricos e conceptuais sobre os quais os estudos sobre o transnacionalismo, até há pouco muito divididos, atingiram um certo consenso. Esses aspectos são indicadores de um certo progresso, na medida em que a evidência dos dados e a reflexão que esta posteriormente veio a suscitar fizeram com que investigadores dos mais variados quadrantes se pusessem gradualmente de acordo quanto à consistência de determinados argumentos e à fragilidade de outros.

\section{Convergências}

As cinco conclusões a seguir referidas parece terem obtido um certo consenso entre os especialistas deste campo.

${ }^{1}$ O presente texto é uma tradução do artigo "Conclusion: Theoretical Convergencies and Empirical Evidence in the Study of Immigrant Transnationalism”, International Migration Review, 37(3), 2003: 874-92. Agradecemos ao autor a autorização concedida para a inclusão neste número da RCCS. 
1. O transnacionalismo representa uma perspectiva nova, não um novo fenómeno A discussão sobre se há "algo de novo" nas práticas hoje chamadas transnacionais parece ter ficado decidida com o reconhecimento de que existem muitos precedentes na história da imigração, mas que, ao mesmo tempo, faltava uma perspectiva teórica convincente que viesse iluminar-lhes as semelhanças por forma a poderem ser identificadas como sendo, de algum modo, “o mesmo". $\mathrm{Na}$ ausência desta perspectiva, esses exemplos não seriam mais que incidentes históricos isolados, sem qualquer progressão cumulativa passível de permitir a criação de novas tipologias ou a possibilidade de previsão. Neste ponto, convém recordar a clássica análise da "falácia do vislumbre", de Merton, que submete as ideias novas a duas acusações de sentido contraditório: a de que, se são novas, elas não são, efectivamente, verdadeiras, e se são verdadeiras é porque não são, de facto, novas. Segundo Merton, quando "[...] uma ideia é formulada de um modo tão decidido e tão enfático que se torna impossível aos seus contemporâneos ignorá-la, torna-se então fácil encontrar prenúncios dela” (Merton, 1968: 16). Robert Smith deixa isso muito claro quando observa que "[...] se no passado existiram transnacionais que como tal não foram reconhecidos, cabe então ao prisma transnacional realizar um trabalho analítico novo que é facultar um modo de ver o que antes lá estava sem ser visto" (Smith, 2003: 1).

Um ponto de acordo secundário mas importante é o reconhecimento de que, embora existam na história da imigração exemplos de transnacionalismo, o fenómeno recebeu um forte impulso com o advento das novas tecnologias na área dos transportes e das telecomunicações, que vieram facilitar enormemente a comunicação rápida através das fronteiras nacionais e a grandes distâncias. Por mais fortes que fossem, no passado, as motivações dos imigrantes para manter os laços - económicos, políticos ou culturais - com os respectivos países de origem, os meios que tinham ao dispor para o conseguirem eram bastante escassos em comparação com aqueles de que hoje em dia dispõem os imigrantes. Este facto explica em boa parte, se não na totalidade, a densidade e a complexidade atingidas pelo transnacionalismo imigrante contemporâneo, sendo além disso responsável pela sua descoberta enquanto fenómeno merecedor de atenção académica (Guarnizo, 2003; Levitt, 2001; Kivisto, 2001).

\section{O transnacionalismo é um fenómeno popular de base}

Se várias das tipologias anteriormente existentes falavam de um transnacionalismo "a partir de cima" e de um transnacionalismo "a partir de baixo", referindo-se o primeiro às actividades dos governos e das empresas multi- 
nacionais, o grosso destes estudos centra-se nas iniciativas de gente comum visando estabelecer laços duradouros para além das fronteiras nacionais, no plano económico e não só. Da mesma maneira, existe o reconhecimento, devidamente ilustrado pelo artigo de Steven Vertovec, de que os imigrantes não são os únicos actores privados envolvidos neste tipo de acção (Vertovec, 2003). Movimentos de base como as associações não-governamentais e os activistas que se batem pelos direitos humanos, pelo ambiente e por outras causas globais, contribuíram igualmente para a proliferação de redes transfronteiriças "a partir de baixo" (Keck e Sikkink, 1998).

Por este motivo, parece ser defensável uma tipologia que distinga entre as actividades dos Estados nacionais, das instituições multicêntricas globais, e dos actores não-empresariais privados. Uma tal tipologia, proposta em anterior artigo e reproduzida na Figura 1, distingue entre as actividades internacionais dos governos e de outras instituições identificadas com um determinado Estado, as iniciativas multinacionais de instituições globais como sejam a Igreja Católica e diversas agências das Nações Unidas, e ainda as acções transnacionais levadas a cabo por actores não-governamentais e não-empresariais da sociedade civil. O transnacionalismo imigrante encaixa-se nesta última categoria.

É claro que, como observa Rainer Bauböck, esta tipologia não é intocável, podendo elaborar-se outras como seu complemento ou em alternativa (Bauböck, 2003). No entanto, os fins com que esta classificação foi proposta permanecem válidos, independentemente das modificações que ela venha, eventualmente, a sofrer. Assim, ela serve para salientar dois aspectos. O primeiro é que o conceito de transnacionalismo, tal como é utilizado na literatura actualmente produzida, se refere antes de mais às actividades transfronteiriças de actores de base privados, neles se incluindo os imigrantes. O segundo aspecto é que faz falta uma linguagem que distinga estas actividades das dos grandes aparelhos burocráticos e de outras instituições que há muito fazem parte da nossa paisagem global. Na ausência desta distinção, o conceito de transnacionalismo transforma-se numa mistura confusa dos mais diversos fenómenos, perdendo a sua capacidade heurística de sinalizar um processo social bem delimitado e distinto.

\section{Nem todos os imigrantes são transnacionais}

O conjunto antropológico de estudos que lançou efectivamente o transnacionalismo enquanto perspectiva nova era de molde a sugerir que se tratava de um fenómeno comum a todas as comunidades imigrantes contemporâneas. Isso justificou, em parte, que se rebaptizasse os imigrantes com a designação de "transmigrantes", na medida em que haviam deixado de 
FIGURA 1 - Actividades transfronteiriças de diferentes tipos de actores

\begin{tabular}{|c|c|c|c|}
\hline \multirow{2}{*}{ Actividades } & \multicolumn{3}{|c|}{ Áreas } \\
\hline & Política & Económica & Sócio-cultural \\
\hline Internacionais & $\begin{array}{l}\text { Estabelecimento de } \\
\text { embaixadas e or- } \\
\text { ganização de } \\
\text { missões diplo- } \\
\text { máticas no es- } \\
\text { trangeiro por } \\
\text { parte dos gover- } \\
\text { nos nacionais }\end{array}$ & $\begin{array}{l}\text { Campanhas de ex- } \\
\text { portação levadas } \\
\text { a cabo por orga- } \\
\text { nizações agro- } \\
\text { pecuárias e das } \\
\text { pescas de países } \\
\text { específicos }\end{array}$ & $\begin{array}{l}\text { Programas para } \\
\text { deslocação e in- } \\
\text { tercâmbio orga- } \\
\text { nizados por uni- } \\
\text { versidades sedia- } \\
\text { das em países es- } \\
\text { pecíficos }\end{array}$ \\
\hline Multinacionais & $\begin{array}{l}\text { Organizações per- } \\
\text { tencentes às Na- } \\
\text { ções Unidas e } \\
\text { outras, encarre- } \\
\text { gadas da moni- } \\
\text { torização e da } \\
\text { melhoria de áre- } \\
\text { as especializadas } \\
\text { do viver global }\end{array}$ & $\begin{array}{l}\text { Actividades de pro- } \\
\text { dução e comer- } \\
\text { cialização de } \\
\text { empresas globais } \\
\text { com lucros de- } \\
\text { pendentes de } \\
\text { múltiplos merca- } \\
\text { dos nacionais }\end{array}$ & $\begin{array}{l}\text { Escolas e missões } \\
\text { patrocinadas em } \\
\text { diversos países } \\
\text { pela Igreja Cató- } \\
\text { lica e outras reli- } \\
\text { giões de implan- } \\
\text { tação global }\end{array}$ \\
\hline
\end{tabular}

Transnacionais

a) Associações não- governamentais criadas com o fim de monitorizar os direitos humanos à escala global

b) Associações cívicas da terra natal, criadas pelos imigrantes com o fim de promover a melhoria das comunidades de origem a) Boicotes organizados em países do Primeiro Mundo por activistas de base para obrigar as multinacionais a melhorar as suas práticas laborais no Terceiro Mundo

b) Empresas criadas por imigrantes visando a importação/exportação de bens de ou para os seus países de origem a) Movimentos de solidariedade de base visando promover a protecção e a assistência a crianças das nações pobres

b) Concursos de beleza e selecção de grupos musicais ou de artistas nas comunidades de imigrantes, para actuar em festas anuais organizadas na terra natal 
trilhar a via tradicional da assimilação para enveredar em massa por actividades "multicapilares" empreendidas para além das fronteiras nacionais (Basch et al., 1994).

Não surpreende que o entusiasmo intelectual inicialmente associado à descoberta deste fenómeno tenha levado a que se exagerasse o seu âmbito. O problema das amostragens com base na variável dependente, associado ao método do estudo de caso, já foi identificado como sendo responsável por obscurecer a ausência do transnacionalismo no quotidiano de muitos imigrantes (Smith, 2003; Portes, 2001). A investigação subsequente veio mostrar que só uma minoria dos imigrantes se caracteriza por um envolvimento regular em actividades transnacionais, e que o próprio envolvimento ocasional não constitui uma prática universal (Guarnizo, 2003; Landolt, 2001). Embora muitas acções, como por exemplo o envio pontual de remessas ou a visita ao país natal, caibam sem dúvida naquilo que é rotulado como transnacionalismo, elas não justificam, por si sós, a cunhagem de um termo novo. Com efeito, trata-se de actividades a que os imigrantes se dedicam desde tempos imemoriais. Encontramo-nos, assim, perante o paradoxo que é o facto de o transnacionalismo, enquanto prisma teórico novo no campo da imigração, se basear nas actividades de apenas uma minoria dos membros da população em causa.

\section{O transnacionalismo imigrante tem consequências macro-sociais}

Apesar da reduzida dimensão numérica dos envolvidos, as acções transnacionais realizadas com regularidade por um dado conjunto de activistas, somadas às actividades pontuais de outros imigrantes, acabam por resultar num processo de significativo impacto económico e social para as comunidades e para as próprias nações em causa. Se, numa perspectiva individual, o acto de enviar remessas, de comprar uma casa na terra natal, ou de até aí viajar de vez em quando, acarreta consequências meramente pessoais, no cômputo geral esses actos podem alterar a fortuna e a cultura dessas terras e, inclusivamente, dos países a que estas pertencem. Estas acções e outras semelhantes, multiplicadas milhares de vezes, traduzem-se num fluxo monetário passível de se tornar uma fonte primacial de moeda estrangeira para os países de emigração, em investimentos que sustentam a indústria da construção nessas nações, e em novas práticas culturais que vêm alterar radicalmente os sistemas de valores e o quotidiano de vastas regiões (Levitt, 2001; Itzigsohn et al., 1999; Ostergaard-Nielsen, 2001).

Luis Guarnizo refere a bem reveladora ironia que é as remessas enviadas por um trabalhador ou trabalhadora imigrantes preocupados com o bem-estar da família que ficou na sua terra serem "amealhadas" pelo governo 
do país de emigração como fonte certa de moeda estrangeira e, inclusivamente, utilizadas como garantia para contrair empréstimos internacionais. Os magos financeiros que mandam no mundo capitalista aprenderam a confiar não só nas remessas actuais mas também na expectativa de fluxos regulares no futuro como critério indicador de confiança para concessão de crédito a Estados-nação e da elegibilidade destes para novos investimentos. Deste modo, as diásporas geradas por uma miríade de decisões isoladas de homens e mulheres desejosos de melhorar as suas oportunidades de vida pessoais transformam-se, com o tempo, numa componente-chave das exportações das nações de emigração e num dos principais meios que têm ao seu dispor para continuarem integradas na economia mundial (Guarnizo, 2003; Roberts et al., 1999; Goldring, 1992).

É esta a principal razão pela qual, nos últimos anos, os países de emigração têm revelado um interesse tão grande pelos seus expatriados, apressando-se a aprovar legislação relativa à dupla nacionalidade e à dupla cidadania e a conceder aos emigrantes representação nos órgãos legislativos nacionais. Quanto a este aspecto, os estudos existentes são concordantes, mostrando que os mais diversos países, desde a Eritreia à Colômbia e da Turquia ao México, deram passos no sentido de manter ligações duradouras com as respectivas diásporas e de incentivar as remessas e os investimentos que delas lhes chegam (Al-Ali et al., 2001; Guarnizo et al., 1999; Ostergaard-Nielsen, 2001, 2003; Fitzgerald, 2000; Smith, 1998). Um tal activismo governamental dá origem a outra ocorrência paradoxal, já descrita por Robert e seus colegas (1999). Servindo-se da famosa tipologia de Hirschman, estes autores observam que, enquanto, antes da sua deslocação para o estrangeiro, os imigrantes se viam abandonados e eram mesmo reprimidos, a sua saída veio conceder-lhes a voz que politicamente nunca haviam tido, o que foi resultado directo dos esforços dos seus próprios governos no sentido de preservar a lealdade aos países de origem.

As acções esforçadas dos governos visando promover e manter o transnacionalismo, sobretudo no campo económico, poderiam sugerir que a causa maior dessas actividades foram as políticas oficiais. Mas seria errado tirar tal conclusão, pois o surto de actividades transnacionais em todos os campos deveu-se às iniciativas dos próprios imigrantes, que para esse efeito mobilizaram as suas redes de longo alcance. Como observa Vertovec (2003), os conceitos de redes sociais e de capital social encontram no campo dos estudos transnacionais uma aplicação singularmente fértil, na medida em que estas actividades se fundam e sustentam invariavelmente em recursos sociais de base que funcionam como compensação para a escassez dos meios político-económicos. 
Por norma, os governos só fizeram a sua entrada neste campo após um determinado conjunto de actividades transnacionais se encontrar já consolidado pela iniciativa popular. Essa entrada não deixou de ser problemática: se é verdade que as políticas oficiais podem promover e desenvolver iniciativas transnacionais, elas podem também, apesar dessa aparência benévola, comprometer a sua viabilidade através de tentativas de cooptação e de manipulação. É por esse motivo que muitas organizações cívicas e de solidariedade, criadas através dos esforços de activistas imigrantes de base, se mantêm firmemente "apolíticas", procurando manter-se distantes das solicitações oficiais para não comprometerem os objectivos das associações (Landolt et al., 1999; Smith, 1998).

\section{O alcance e as formas do activismo transnacional variam com os contextos de saída e de acolhimento.}

Este aspecto tem-se revelado mais pacífico, já que desde logo se reconheceu que as actividades transnacionais são bastante heterogéneas e que variam, tanto em popularidade como na sua respectiva natureza, de umas comunidades imigrantes para outras. Um dos principais factores determinantes desta variação são os contextos de saída e de acolhimento de determinados grupos específicos, os quais condicionam a propensão destes para se dedicarem a iniciativas transfronteiriças ou, inclusivamente, para as adoptarem como modalidade principal do processo de adaptação económica. Uma das constatações iniciais do estudo resumido na secção que se segue é que os imigrantes das áreas urbanas que vêm fugidos de situações de violência generalizada tendem a procurar uma integração rápida na sociedade anfitriã e a evitar o envolvimento activo com a que deixaram para trás. Os imigrantes colombianos são um bom exemplo disso (Guarnizo et al., 1999). Inversamente, os imigrantes provenientes de pequenas cidades e meios rurais e cujo país de origem vive uma situação de paz evidenciam uma tendência significativamente maior para se dedicarem a aç̧ões transnacionais de carácter político e cívico de apoio aos respectivos países. Os imigrantes salvadorenhos dos Estados Unidos da América constituem, a este respeito, um exemplo bem conhecido (Landolt et al., 1999; Landolt, 2001; Menjivar, 2000).

As formas como os imigrantes se incorporam na sociedade anfitriã também afectam a sua propensão para se dedicarem a iniciativas transnacionais. Os dados disponíveis são de molde a sugerir que os imigrantes que se dispersam e cuja presença discreta os protege de discriminações têm menos tendência a dedicar-se a estas acções. Por outro lado, as actividades transnacionais florescem no seio de comunidades altamente concentradas, e em 
especial daquelas que foram alvo de um acolhimento hostil por parte das autoridades e dos cidadãos da sociedade anfitriã. As grandes concentrações co-étnicas geram oportunidades múltiplas de empreendimentos transnacionais, ao passo que a discriminação generalizada vinda de fora obriga o grupo a voltar-se para dentro, incentivando ao mesmo tempo os contactos com as comunidades de origem.

Nestes contextos, as associações cívicas e as actividades culturais transnacionais oferecem um alívio para a hostilidade exterior e protegem a dignidade pessoal por ela ameaçada. A experiência dos haitianos, dominicanos e mexicanos nos Estados Unidos e dos indianos e paquistaneses na Grã Bretanha, relatada em numerosos estudos etnográficos, dá testemunho destas tendências (Glick Schiller e Fouron, 1999; Stepick, 1998; Stepick et al., 2001; Itzigsohn et al., 1999; Goldring, 1992; Roberts et al., 1999; Ballard, 2000).

\section{Dados quantitativos}

Esta secção sintetiza os resultados do Comparative Immigrant Entrepreneurship Project (Projecto Comparado sobre o Empreendedorismo Imigrante - CIEP), o mais vasto inquérito até hoje realizado com o intuito explícito de recolher dados factuais sobre as actividades transnacionais de tipo económico, político e sócio-cultural dos grupos imigrantes. Embora já tenham sido publicitados noutros lugares alguns registos parciais dos dados apurados, o resumo da totalidade dos resultados do estudo não se encontra disponível em nenhuma outra publicação. Apresento-os aqui para facultar um contraponto empírico aos argumentos teóricos anteriormente adiantados. O CIEP foi um esforço de cooperação entre universidades das costas Leste e Oeste dos Estados Unidos da América, englobando trabalho de campo qualitativo e quantitativo levado a cabo entre o Outono de 1996 e o Inverno de $1998 .^{2}$

A fase inicial do estudo constou de entrevistas a 353 informantes-chave distribuídos por seis zonas de concentração imigrante nos Estados Unidos (duas por cada uma das nacionalidades seleccionadas) e seis cidades no estrangeiro, incluindo a capital de cada um dos países de origem escolhidos. A segunda fase do projecto foi um inquérito levado a efeito junto das três comunidades imigrantes-alvo nas suas principais zonas de concentração nos Estados Unidos. O inquérito foi realizado em duas fases. A primeira

\footnotetext{
${ }^{2} \mathrm{O}$ projecto baseou-se em acordos de cooperação estabelecidos entre as universidades de Johns Hopkins, California-Davis, e Brown. Nos estádios finais da sua realização, o projecto esteve sediado no Centro para as Migrações e o Desenvolvimento da Universidade de Princeton.
} 
consistiu numa amostragem aleatória polietápica que tomou o quarteirão urbano como unidade primária da amostragem (PSU) e numa amostragem aleatória sistemática dos cabeças de agregado dos grupos nacionais seleccionados em cada quarteirão. A segunda fase foi uma amostragem não-probabilística feita com base em dados prestados pelos informantes no decurso da primeira fase e realizada por bola de neve. Esta parte do inquérito, que recebeu a designação de "estrato especial" (Kish, 1967: 409), visou identificar os imigrantes envolvidos em actividades empresariais em geral e em actividades transnacionais em particular. Este estrato garante a presença de um número suficiente de empresários transnacionais para efeito da análise quantitativa, mas torna a amostragem enviesada a favor destes.

Para compensar esse enviesamento, as análises estatísticas aos dados do CIEP ponderaram casos não-probabilísticos de acordo com a proporção que os empregados por conta própria representam na população de chefes de agregado adultos e activos do grupo nacional relevante de cada zona inquirida. Esse procedimento evita que se perca informação valiosa, ao mesmo tempo que impede que haja estimativas enviesadas em resultado de diferentes probabilidades de selecção (Kish, 1967: 407-409; Sudman, 1983). As amostras ponderadas daí resultantes podem considerar-se representativas dos grupos nacionais de imigrantes-alvo, nas respectivas zonas de concentração. Contudo, as probabilidades de selecção variam de zona para zona, devido à dimensão desigual das comunidades imigrantes em cada uma delas. Para corrigir este problema na análise conjunta da totalidade da amostra, desenvolvemos uma segunda série de ponderações. Estas são o inverso da fracção amostral, definida como o rácio entre a amostra e a população de cabeças de agregado do grupo nacional-alvo de cada zona. O Censo da População e da Habitação dos Estados Unidos realizado em 1990 facultou-nos a informação necessária para calcular estas fracções amostrais (Frankel, 1983; Sudman, 1983).

O Quadro 1 apresenta as amostras, as populações relevantes, as fracções amostrais, e as taxas de auto-emprego (para ponderação do estrato não-probabilístico dos empresários). A amostra ajustada pode ser considerada representativa de 187.228 agregados colombianos, dominicanos e salvadorenhos em cinco zonas de concentração diferentes. Estas nacionalidades foram seleccionadas, em parte, devido à sua dimensão, já que se estima que cada uma delas conta, actualmente, para cima de um milhão de membros e que, no conjunto, elas representam cerca de um quinto da totalidade dos imigrantes da América Latina nos Estados Unidos (Farley, 2001; Landolt, 2001; Portes e Guarnizo, 1991; Guarnizo et al., 1999). Mais importante do que isso, os contextos de saída e de acolhimento destes grupos são bastante 
diversos, não obstante as origens culturais e linguísticas comuns. Isso permite-nos examinar o modo como estas variáveis macro-sociais - as condições no país natal e as modalidades de incorporação na sociedade anfitriã afectam o surto do transnacionalismo e a sua natureza.

\section{QUADRO 1 - Distribuição da amostragem CIEP por nacionalidade, zona e tipo de actividade económica}

\begin{tabular}{|c|c|c|c|c|}
\hline \multirow{2}{*}{$\begin{array}{l}\text { Nacionalidade e local da realização } \\
\text { do estudo }\end{array}$} & \multicolumn{2}{|c|}{ Número de casos } & \multirow{2}{*}{$\begin{array}{c}\text { Fracção } \\
\text { amostral } \\
\%\end{array}$} & \multirow{2}{*}{$\begin{array}{c}\text { Percentagem } \\
\text { empregada } \\
\text { por conta própria } \\
\text { (Censo de 1990) }\end{array}$} \\
\hline & Amostragem & População & & \\
\hline \multicolumn{5}{|l|}{ Colombianos: } \\
\hline Queens, Nova lorque & 311 & 26.750 & 1,16 & 8,0 \\
\hline \multicolumn{5}{|l|}{ Dominicanos: } \\
\hline Providence, Rhode Island & 159 & 2.296 & 6,92 & 4,0 \\
\hline Washington Heights, Nova lorque & 259 & 88.930 & 0,29 & 7,8 \\
\hline Subtotal & 418 & 91.226 & - & $7,7^{a}$ \\
\hline \multicolumn{5}{|l|}{ Salvadorenhos: } \\
\hline Los Angeles, California & 240 & 57.076 & 0,42 & 7,4 \\
\hline Washington, DC & 233 & 12.176 & 1,91 & 5,3 \\
\hline Subtotal & 473 & 69.252 & - & $7,0^{a}$ \\
\hline Total & 1202 & 187.228 & 0,64 & 7,5 \\
\hline
\end{tabular}

a Média ponderada por população de chefes de agregado adultos do grupo nacional relevante de cada zona.

Os quadros seguintes apresentam uma súmula de resultados retirados da amostragem CIEP e baseados, na sua grande parte, na versão ponderada daquele estudo. As fontes são indicadas sempre que tal se justifica. O Quadro 2 mostra o alcance do transnacionalismo económico, político e sócio-cultural entre os três grupos nacionais de imigrantes. O quadro engloba números correspondentes a uma definição "lata" do conceito, que inclui actividades quer regulares quer ocasionais, e uma definição "estrita", baseada numa participação apenas de tipo regular. No campo económico, o número dos empresários transnacionais restringe-se aos indivíduos que, trabalhando por conta própria, responderam afirmativamente a uma das questões seguintes:

- "O êxito da minha empresa depende do contacto regular com países estrangeiros".

- "O êxito da minha empresa depende de contactos regulares com a Colômbia/a República Dominicana/El Salvador" (conforme o país de origem do inquirido). 
O estudo do transnacionalismo imigrante $\mid 83$

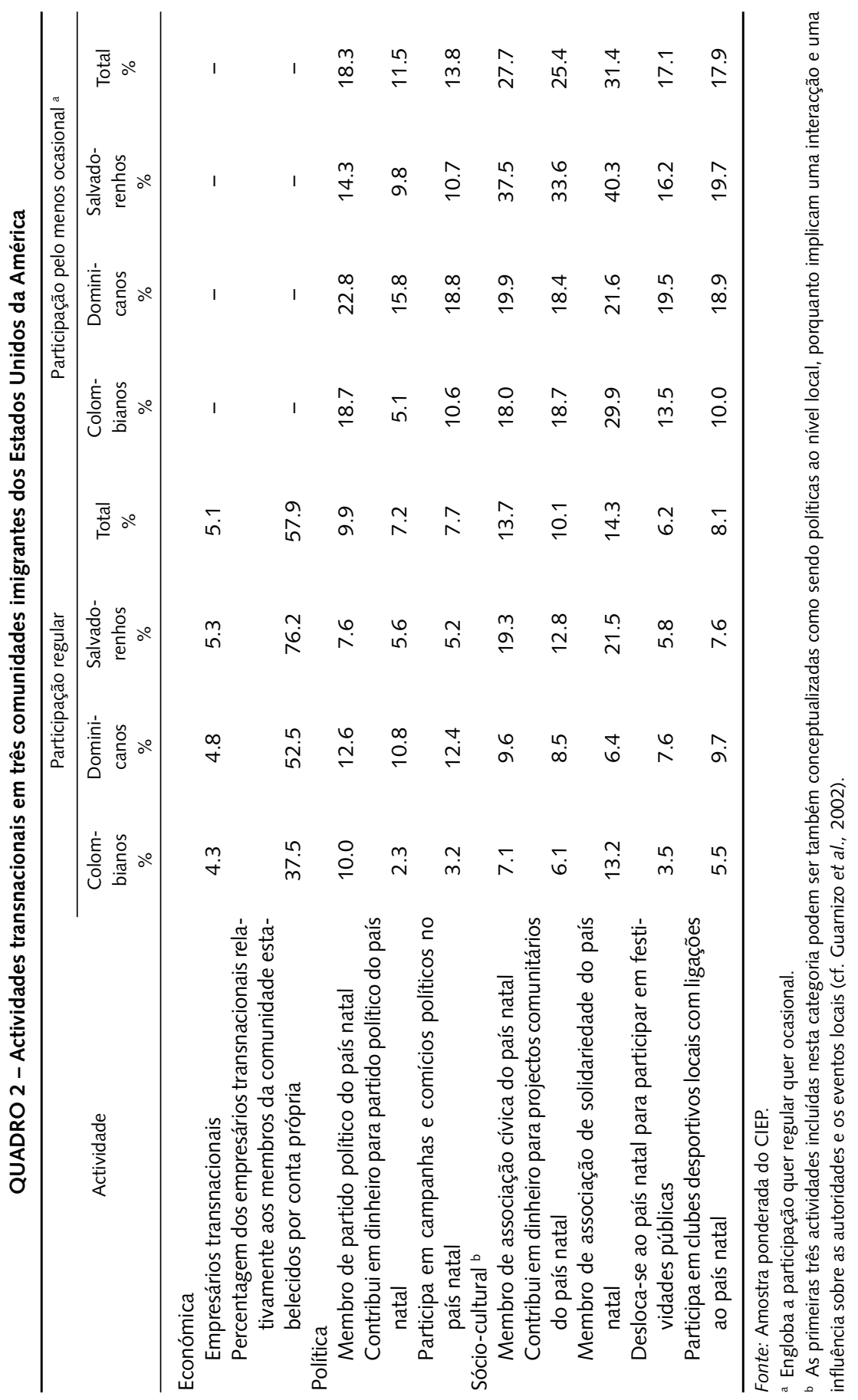


Definidos desta maneira, os empresários transnacionais representam uma pequena minoria da amostra ponderada, não ultrapassando os $6 \% \mathrm{em}$ nenhum dos casos. Este valor contrasta de modo flagrante com as descrições constantes da literatura etnográfica, de onde transparece por vezes a ideia de que, nos nossos dias, as acções transnacionais se tinham tornado a principal forma de adaptação económica dos imigrantes. Note-se, porém, que os transnacionais representam de facto uma percentagem elevada da totalidade dos indivíduos empregados por conta própria nestas comunidades. Assim, se por um lado os imigrantes se tornam empresários, a verdade também é que um número muito significativo deles o faz servindo-se dos contactos que mantêm com o estrangeiro, e em particular com as nações de que são oriundos.

A mesma conclusão geral se verifica no caso das actividades políticas ou sócio-culturais. Os activistas políticos transfronteiriços com actividade regular constituem uma pequena minoria, não ultrapassando $10 \%$ da totalidade da amostra ponderada e $15 \%$ no caso do grupo imigrante mais predisposto a este tipo de participação (o dos dominicanos). Embora a participação ocasional seja mais comum, mais uma vez ela não chega a ultrapassar um quinto da amostra para quase todos os casos considerados. O envolvimento nas actividades cívicas é ligeiramente mais comum, especialmente entre os salvadorenhos, mas na amostra total apenas um terço participou pelo menos a título ocasional.

Tomados no seu conjunto, estes resultados indicam que o transnacionalismo não constitui o modo de adaptação normativo ou dominante destes grupos de imigrantes. Quando no novo país, a maior parte dos seu membros parece prosseguir as suas vidas num relativo esquecimento daquilo que fora a sua experiência anterior. Nesta medida, encontra-se aqui fundamento para a posição "canónica" da teoria da imigração, que acentua a assimilação dos imigrantes pela sociedade anfitriã. Acresce que o reconhecimento de que o transnacionalismo não é um fenómeno universal deve ser alargado por forma a reconhecer também que, pelo menos no caso de alguns imigrantes, ele se encontra quase ausente.

Os dados mostram efectivamente que as actividades transnacionais são uma realidade, que existe um núcleo de empresários e activistas transnacionais empenhados naquilo que fazem, e que há uma minoria considerável de imigrantes envolvidos a título pelo menos ocasional. Além disso, os resultados apresentados no Quadro 3 questionam de uma maneira importante uma eventual aceitação apressada das teses assimilacionistas, com base em distribuições de frequência simples. Este quadro sintetiza os dados apurados quanto aos factores determinantes do transnacionalismo económico, 


\section{QUADRO 3 - Factores determinantes do transnacionalismo entre os imigrantes latino-americanos dos Estados Unidos da América, 1998}

\begin{tabular}{|c|c|c|c|c|c|}
\hline \multirow[t]{2}{*}{ Preditores $^{\mathrm{a}}$} & \multicolumn{2}{|c|}{$\begin{array}{c}\text { Económica } \\
\text { (Empreendedores } \\
\text { transnacionais) }\end{array}$} & \multicolumn{2}{|c|}{$\begin{array}{c}\text { Política } \\
\text { (Definição estrita) }^{c}\end{array}$} & \multirow{2}{*}{$\begin{array}{c}\begin{array}{c}\text { Sócio- } \\
\text {-culturald }\end{array} \\
\begin{array}{c}\text { Coefi- } \\
\text { ciente }\end{array}\end{array}$} \\
\hline & $\begin{array}{l}\text { Coefi- } \\
\text { ciente }\end{array}$ & $p^{e}$ & $\begin{array}{l}\text { Coefi- } \\
\text { ciente }\end{array}$ & $\begin{array}{l}\text { \% Varia- } \\
\text { çãof }\end{array}$ & \\
\hline \multicolumn{6}{|l|}{ Demográficas } \\
\hline Idade & .013 & - & $.101^{\prime}$ & 10.6 & -.008 \\
\hline Idade ao quadrado & - & - & $-.001^{\prime}$ & -0.1 & - \\
\hline Sexo (masculino) & $1.035^{\mathrm{m}}$ & .08 & $1.209^{k}$ & 235.3 & $.697^{\prime}$ \\
\hline Estado civil & $.440^{\mathrm{m}}$ & .03 & .118 & 12.6 & - \\
\hline Número de filhos & -.049 & - & - & $.120^{1}$ & \\
\hline \multicolumn{6}{|l|}{ Capital humano } \\
\hline Instrução (em anos) & $.114^{\mathrm{m}}$ & .01 & - & - & $.402^{\prime}$ \\
\hline Ensino Secundário completo & - & - & $1.003^{m}$ & 172.7 & - \\
\hline Grau superior & - & - & .324 & 38.3 & - \\
\hline Ex-executivo ou profissão liberal & $1.191^{m}$ & .10 & - & - & .375 \\
\hline \multicolumn{6}{|l|}{ Assimilação } \\
\hline Anos de residência nos EUA & $.036^{k}$ & .003 & $.034^{\mathrm{m}}$ & 3.5 & $.018^{\mathrm{j}}$ \\
\hline Cidadania americana & - & - & -.041 & - & .141 \\
\hline Foi alvo de discriminação nos EUA & .308 & - & - & - & $.287^{k}$ \\
\hline Mobilidade social descendente ${ }^{g}$ & $.402^{1}$ & -.03 & -.058 & - & - \\
\hline \multicolumn{6}{|l|}{ Redes sociais } \\
\hline Dimensão & $.111^{\mathrm{m}}$ & .01 & $.095^{\mathrm{m}}$ & 10.0 & - \\
\hline Âmbito ${ }^{h}$ & .226 & - & -.084 & - & - \\
\hline Com expectativa de regresso & - & - & $.440^{\mathrm{m}}$ & 55.3 & $.303^{\mathrm{k}}$ \\
\hline \multicolumn{6}{|l|}{ Nacionalidade } \\
\hline Colombiana & $-1.519^{m}$ & -.05 & $-1.212^{m}$ & -70.2 & - \\
\hline Dominicana & - & - & - & - & $.661^{1}$ \\
\hline Salvadorenha & $1.097^{m}$ & .09 & -.018 & - & $.920^{1}$ \\
\hline Constante & -6.235 & & -5.813 & & - \\
\hline Coeficientes de determinação múltipla² & .256 & & .104 & & .167 \\
\hline
\end{tabular}

a Os preditores não incluídos em cada uma das regressões vêm indicados com um hífen na coluna assinalada "coeficiente". Omitem-se alguns dos preditores da regressão do transnacionalismo sócio-económico.

${ }^{b}$ Regressão logística das probabilidades de log. de empreendorismo transnacional. Fonte: Portes et al., 2002.

c Regressão binomial negativa do número de actividades políticas, eleitorais e cívicas a que os inquiridos se dedicam regularmente. Fonte: Guarnizo et al., 2002.

d Regressão logit hierárquica de um índice aditivo de participação ocasional ou regular no conjunto das actividades sócio-culturais enumeradas no Quadro 2. A participação regular nas três primeiras actividades indicadas está também incluída na definição de transnacionalismo político. Amostra não-ponderada do CIEP. Fonte: Itzigsohn e Saucedo, 2002.

e Aumento/Diminuição da probabilidade líquida de transnacionalismo económico associado a um aumento de uma unidade de cada um dos preditores. Omitem-se os efeitos não-significativos.

${ }^{f}$ Aumento/Diminuição da percentagem de actividades políticas transnacionais de tipo regular a que os inquiridos se dedicam, associado a um aumento de uma unidade de cada um dos preditores. Omitem-se os efeitos não-significativos.

${ }^{g}$ Rácio entre a última ocupação do país de origem e a primeira ocupação tida nos EUA, ambas codificadas segundo uma escala hierárquica com cinco níveis.

h Rácio entre os vínculos não-locais e locais na cidade de residência dos inquiridos.

'A nacionalidade de referência está assinalada por um hífen na coluna "Coeficiente". No caso das regressões do transnacionalismo económico e político, a categoria de referência é a dominicana. No caso do transnacionalismo sócio-cultural, a categoria de referência é a colombiana.

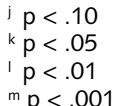


político e sócio-cultural. Nos caso dos dois primeiros, a análise centra-se na participação de tipo regular e prolongada; no caso do transnacionalismo sócio-cultural, ela engloba o envolvimento tanto regular como ocasional. Os métodos da análise também variam. No caso das actividades económicas, os efeitos preditivos são indicados por coeficientes logísticos binomiais e probabilidades associadas; no caso do envolvimento político, resultam de regressões binomiais negativas (RBN) e de variações percentuais associadas, verificadas no total da participação transnacional regular; quanto ao transnacionalismo sócio-cultural, os efeitos sobre um índice compósito de participação regular e ocasional são dados por coeficientes de uma regressão logit hierárquica.

Não obstante estas diferenças, verifica-se uma convergência significativa naquilo que os resultados nos dizem acerca das determinantes do fenómeno. Uma perspectiva assimilacionista convencional leva a esperar que as actividades transnacionais sejam de tipo transitório e estejam associadas aos sectores mais recentes e marginais de uma determinada comunidade imigrante - ou seja, às pessoas de menor instrução e com uma maior tendência de mobilidade social descendente. Trata-se daqueles indivíduos que teriam todos os incentivos para manter laços regulares com os respectivos países. Mas os dados apontam no sentido contrário: seja qual for a actividade em apreço, é maior a probabilidade de participação entre os imigrantes com nível de instrução mais elevado. Cada ano de frequência da escola faz aumentar em $1 \%$ a probabilidade do empreendedorismo transnacional, e o diploma de conclusão do ensino secundário implica um aumento de $173 \%$ no número das actividades políticas transnacionais de tipo regular.

Ainda mais reveladores são os efeitos das variáveis convencionalmente associadas à assimilação. A aquisição da cidadania americana não reduz significativamente os níveis da participação transnacional, que aumentam com o número dos anos de residência nos Estados Unidos. Assim, e por exemplo, a cada ano adicional passado nos EU corresponde um aumento de $3,5 \%$ no número das actividades políticas transnacionais de tipo regular. Do mesmo modo, a mobilidade ocupacional de sentido descendente não produz qualquer efeito sobre o transnacionalismo político, reduzindo inclusivamente a probabilidade de o imigrante se tornar um empreendedor transnacional. As actividades transnacionais não são, por conseguinte, um reduto dos pobres e dos marginalizados. Pelo contrário, andam sistematicamente associadas a recursos mais elevados em termos de capital humano: mais instrução, mais anos de experiência nos Estados Unidos, e um estatuto ocupacional mais alto. 
Outros coeficientes do Quadro 3 completam o cenário no que respeita aos factores determinantes do transnacionalismo. Esses elementos são de molde a mostrar que as actividades em causa são realizadas, de uma forma esmagadora, por pessoas do sexo masculino e casadas. O factor sexo revela, por si só, uma influência decisiva, sendo que os elementos do sexo masculino se acham muito mais representados no número dos empreendedores e dos activistas sócio-políticos com actividade transnacional. No que concerne às actividades políticas transfronteiriças, a participação dos imigrantes do sexo masculino ultrapassa a participação feminina em 200\%. Este predomínio é complementado pelo estado civil, como indicam os elevados coeficientes positivos relativos ao matrimónio e ao número de filhos para as diferentes formas de transnacionalismo.

Finalmente, além do capital humano, o capital social desempenha também um papel significativo em todo este processo. Os imigrantes com melhor inserção nas respectivas redes de relacionamento têm muito maior probabilidade de se tornarem activistas transnacionais. Cada vínculo social adicional faz aumentar em $1 \%$ a probabilidade de empreendedorismo transnacional, e em $10 \%$ o número das actividades políticas transnacionais com periodicidade regular. É interessante notar que não é o tipo de vínculos sociais, mas sim o seu número absoluto, que aqui desempenha o papel fundamental. Não importa muito se as redes imigrantes são de âmbito local ou extralocal; o que importa, para as actividades transfronteiriças, é o tamanho delas. Estes resultados são complementados pela constatação de que os imigrantes cujos parentes e amigos esperam que regressem à terra têm uma probabilidade significativamente maior de tomar parte em iniciativas políticas e sócio-culturais no respectivo país de origem.

Controlado esta amplo conjunto de preditores, verificam-se ainda grandes diferenças entre os três grupos nacionais de imigrantes do estudo do CIEP. Usando os dominicanos como categoria de referência, vemos que os salvadorenhos evidenciam uma probabilidade significativamente mais elevada de se tornarem empreendedores transnacionais, ao passo que essa probabilidade é muito menor no caso dos colombianos. Dominicanos e salvadorenhos não diferem grandemente no número total das actividades políticas transfronteiriças a que se dedicam, mas ambos os grupos mostram uma probabilidade de participação muito mais alta do que a dos colombianos. Tomando este último grupo como referência, verifica-se que tanto os dominicanos como os salvadorenhos exibem uma propensão significativamente mais pronunciada para apoiar iniciativas sócio-culturais que os liguem à pátria.

Estas diferenças coincidem com aquilo que se conhece dos contextos de saída e acolhimento dos três grupos. Essa coincidência foi explicada em 
pormenor noutro local (Portes et al., 2002; Landolt, 2001; Guarnizo et al., 2003; Itzigsohn e Saucedo, 2002). Para os objectivos do presente trabalho, o importante a reter é que estas constatações confirmam o consenso teórico quanto à natureza fundamentalmente heterogénea do transnacionalismo imigrante. Este consenso tem a ver principalmente com as formas que o fenómeno assume; os resultados do estudo dessas formas vêm alargar aquele consenso ao mostrar que as suas origens também são heterogéneas, variando de maneira sistemática consoante as proveniências nacionais.

Globalmente, estas constatações são um verdadeiro ensinamento não apenas para os defensores da teoria assimilacionista convencional, mas também para aqueles autores que têm visto no transnacionalismo um novo e poderoso instrumento ao serviço de quantos, a uma escala cada vez mais global, se vêm atingidos pela pobreza e arredados dos seus direitos de participação cívica. De facto, se os nossos resultados mostram que a experiência de discriminação na sociedade anfitriã aumenta significativamente algumas formas de transnacionalismo, e outros resultados indicam que estas actividades podem melhorar a sorte das famílias pobres das terras de origem, a verdade é que os dados aqui reunidos mostram sem qualquer ambiguidade que os imigrantes mais empenhados em iniciativas transfronteiriças não são os mais explorados ou marginalizados. Pelo contrário, o transnacionalismo nas suas diferentes formas emerge da análise como sendo um projecto sobretudo de homens com firme inserção na estrutura familiar - homens com instrução, bons relacionamentos, e uma sólida implantação no país de acolhimento. Mais do que aos recém-chegados e aos que se encontram numa trajectória de mobilidade social descendente, é a estes que se deve a organização de empreendimentos transfronteiriços, o apoio a partidos políticos e a comissões de carácter cívico nos seus países, e a dinamização das festas religiosas e dos eventos culturais e desportivos que ligam cada uma das diásporas emigrantes à respectiva nação.

\section{Resumo e conclusões}

Não obstante o limitado envolvimento dos imigrantes no campo transnacional, é aconselhável o prosseguimento da investigação sobre este tópico, por três ordens de razões. Em primeiro lugar, a existência deste campo cria uma via alternativa na adaptação política e sócio-económica à sociedade anfitriã, não prevista nos modelos de assimilação tradicionais. Como mostram os dados empíricos aqui apresentados, não se trata de a assimilação e o transnacionalismo estarem em contradição, uma vez que muitas vezes são os imigrantes mais estabelecidos e com maior estabilidade quem se dedica a estas actividades. Pelo contrário, as acções ou negócios de carácter trans- 
nacional e o activismo político podem proporcionar formas novas de integração na sociedade anfitriã, a par de um renovado envolvimento no país e na comunidade de origem. Nalguns casos, como por exemplo o das empresas transnacionais de sucesso, estas actividades não só não impedem como reforçam a adaptação bem sucedida ao novo país por parte dos imigrantes e seus descendentes (Portes et al., 2002).

Em segundo lugar, as iniciativas transfronteiriças, mesmo quando conduzidas com carácter ocasional, assumem uma grande importância para as nações de origem. Como refere Luis Eduardo Guarnizo, as remessas e os investimentos dos emigrantes já não constituem um fenómeno marginal, tendo-se, pelo contrário, tornado um dos pilares da estabilidade financeira e das perspectivas de desenvolvimento dos países de emigração. O impacto significativo que as remessas e os contributos da população expatriada podem ter no desenvolvimento das comunidades locais encontra-se bem documentado em estudos de campo realizados em El Salvador (Landolt, 2001), no Brasil (Levitt, 2001), no México (Fitzgerald, 2000) e na Eritreia (Al-Ali et al., 2001), entre outros países.

Em terceiro lugar, não há ainda uma compreensão plena das implicações do fenómeno e das formas que ele pode assumir nos diferentes países. Como revela o artigo de Levitt, o campo do transnacionalismo não é composto exclusivamente por transacções económicas e políticas. É também decisivo, em muitos casos, o papel desempenhado pela presença da religião, cujo alcance e impacto tanto nas nações anfitriãs como nas de origem carece de uma investigação mais aprofundada (Levitt, 2003). O estudo de outros tipos de laços transnacionais, relacionados com movimentos culturais, vínculos científico-profissionais, com as artes e com o desporto, está ainda a dar os primeiros passos. No que concerne às variações verificadas entre os diversos grupos nacionais, a constatação de que três grupos imigrantes linguística e culturalmente tão próximos como são os colombianos, os dominicanos e os salvadorenhos apresentam tamanhas disparidades na extensão e no carácter das respectivas existências transnacionais justifica que se prevejam variações muito maiores para este fenómeno ao nível mundial.

Conforme já ficou dito, o estudo do transnacionalismo tem-se baseado principalmente nos estudos etnográficos. Embora o método do estudo de caso tenha as suas vantagens, incluindo a capacidade de pôr a descoberto algumas realidades escondidas debaixo das aparências e de proporcionar descrições fecundas de certos fenómenos sociais específicos, ele tem também as suas limitações. São precisos mais estudos comparativos e quantitativos sobre o transnacionalismo, assentes em inquéritos ou em estatísticas oficiais agregadas, e por três razões. A primeira será colocar o fenómeno no 
seu contexto devido, fixando-lhe as reais dimensões. Os números relativos ao volume absoluto e relativo das remessas, de que Guarnizo (2003) nos oferece uma súmula, dão-nos uma noção abalizada do peso dessas transferências. Do mesmo modo, a análise dos dados do CIEP faculta-nos uma primeira estimativa fiável do número real de imigrantes envolvidos nestas actividades.

Em segundo lugar, são necessários estudos quantitativos comparados a fim de testar hipóteses sobre os factores determinantes, as formas e as consequências do transnacionalismo. Os conceitos teóricos que Vertovec (2003) dá como relevantes para o estudo do fenómeno, como sejam a inserção, as redes sociais, e o capital social, foram já ilustrados em todo um conjunto de estudos de caso. Contudo, os dados etnográficos não bastam para fixar o verdadeiro significado causal destes conceitos em geral ou de eventuais exemplos nacionais em concreto. Assim, e por exemplo, pode perguntar-se qual será o papel do capital social no surto de empreendedorismo transnacional, uma vez descontados os factores idade, sexo e instrução. Ou qual será o significado das redes sociais para a organização de programas eficazes de assistência na terra natal, uma vez controlados os factores distância geográfica e contexto político dos países de emigração. Mais uma vez, os resultados acima sintetizados facultam alguns dados pertinentes para estas questões, mas é necessária ainda muita investigação adicional.

Em terceiro lugar, são precisos dados longitudinais para examinar a questão crucial da transmissibilidade geracional. O transnacionalismo é sobretudo, ou exclusivamente, um fenómeno das primeiras gerações? Ou será de esperar que os filhos dos imigrantes nele participem em grande número? Várias opções se nos apresentam, desde a perpetuação do campo transnacional ao longo das gerações até ao uso instrumental destas actividades como forma de facilitar a integração com êxito da segunda geração de jovens na sociedade de acolhimento. Já existem dados pontuais sobre cada uma destas opções. No entanto, na ausência de estudos longitudinais mais representativos, pouco mais pode acrescentar-se com autoridade acerca do seu significado.

Em última análise, as perspectivas mais promissoras no sentido de fazer avançar o estudo do transnacionalismo residirão numa eventual combinação de métodos - desde a análise de dados e recenseamentos oficiais já existentes até trabalhos de índole etnográfica, passando por inquéritos longitudinais. A investigação anterior mostra de maneira convincente que o transnacionalismo imigrante existe e que pode adoptar múltiplas formas. Essa investigação conduziu igualmente a uma série de convergências, já devidamente 
referenciadas no início deste artigo. Para se ir além deste patamar e para se ter uma influência duradoura quer sobre as políticas de desenvolvimento, quer sobre a teoria sociológica, há que encontrar, nos próximos anos, uma abordagem metodologicamente mais diversificada.

Tradução de

João Paulo Moreira

\section{Referências Bibliográficas}

Al-Ali, Nadje; Black, Richard; Koser, Khalid (2001), "The Limits to 'Transnationalism': Bosnian and Eritrean Refugees in Europe as Emerging Transnational Communities", Ethnic and Racial Studies, 24(4), 578-600.

Ballard, Roger (2000), "The South Asian Presence in Britain and Its Transnational Connections", comunicação apresentada à International Workshop on Transnational Research, Universidade de Oxford, Julho.

Basch, Linda G.; Glick Schiller, Nina; Blanc-Szanton, Christina (1994), Nations Unbound: Transnational Projects, Post-Colonial Predicaments, and De-Territorialized NationStates. Langhorne, PA: Gordon and Breach.

Bauböck, Rainer (2003), “Towards a Political Economy of Migrant Transnationalism”, International Migration Review, 37(3), 700-723.

Farley, Reynolds (2001), "Immigrants and Their Children: Evidence from the Census Bureau's Recent Survey”, comunicação apresentada à Sessão sobre Migrações Internacionais dos Encontros da American Sociological Association, Anaheim, California, 18-21 Agosto.

Fitzgerald, David (2000), Negotiating Extra-Territorial Citizenship: Mexican Migration and the Transnational Politics of Community. San Diego: Center for Comparative Immigration Studies, University of California, San Diego.

Frankel, Martin (1983), "Sampling Theory", in Peter H. Rossi et al. (orgs.), Handbook of Survey Research. New York: Academic Press, 21-67.

Glick Schiller, Nina; Fouron, Georges E. (1999), "Terrains of Blood and Nation: Haitian Transnational Social Fields", Ethnic and Racial Studies, 22, 340-366.

Goldring, Luin (1992), "La migracion Mexico-EUA y la transnacionalizacion del espacio politico y social: perspectivas desde el Mexico rural”, Estudios Sociologicos, 10(29), 315-340.

Guarnizo, Luis Eduardo (2003), "The Economics of Transnational Living”, International Migration Review, 37(3), 666-699.

Guarnizo, Luis Eduardo; Sanchez, Arturo I.; Roach, Elizabeth (1999), "Mistrusted, Fragmented Solidarity, and Transnational Migration: Colombians in New York and Los Angeles", Ethnic and Racial Studies, 22, 367-396. 
Guarnizo, Luis Eduardo; Portes, Alejandro; Haller, William J. (2003), “Assimilation and Transnationalism Determinants of Transnational Political Action among Contemporary Immigrants”, American Journal of Sociology, 36(3), 766-799.

Itzigsohn, José et al. (1999), "Mapping Dominican Transnationalism: Narrow and Broad Transnational Practices”, Ethnic and Racial Studies, 22, 316-339.

Itzigsohn, José; Saucedo, Silvia Giorguli (2002), "Immigrant Incorporation and Sociocultural Transnationalism”, International Migration Review, 36(3), 766-798.

Keck, Margaret E.; Sikkink, Kathryn (1998), Activists beyond Borders. Ithaca, NY: Cornell UP.

Kish, Leslie (1967), Survey Sampling. New York: Wiley.

Kivisto, Peter (2001), "Theorizing Transnational Immigration: A Critical Review of Current Efforts”, Ethnic and Racial Studies, 24, 549-577.

Landolt, Patricia (2001), "Salvadoran Economic Transnationalism: Embedded Strategies for Household Maintenance, Immigrant Incorporation, and Entrepreneurial Expansion", Global Networks, 1, 217-242.

Landolt, Patricia; Autler, Lilian; Baires, Sonia (1999), “From 'Hermano Lejano' to 'Hermano Mayor': The Dialectics of Salvadoran Transnationalism”, Ethnic and Racial Studies, 22, 290-315.

Levitt, Peggy (2001), “Transnational Migration: Taking Stock and Future Directions”, Global Networks, 1, 195-216.

Levitt, Patricia (2003), “'You Know, Abraham Was Really the First Immigrant': Religion and Transnational Migration”, International Migration Review, 37(3), 847-873.

Menjivar, Cecilia (2000), Fragmented Ties: Salvadoran Immigrant Networks in America. Berkeley: University of California Press.

Merton, Robert King (1968), Social Theory and Social Structure. New York: Free Press (enlarged edition).

Ostergaard-Nielsen, Eva (2001), "Transnational Practices and the Receiving State: Turks and Kurds in Germany and the Netherlands", Global Networks, 1, 261-281.

Ostergaard-Nielsen, Eva (2003), “The Politics of Migrant Transnational Practices”, International Migration Review, 37(3), 760-786.

Portes, Alejandro (2001), "The Debates and Significance of Immigrant Transnationalism”, Global Networks, 1, 181-193.

Portes, Alejandro; Guarnizo, L.E. (1991), "Tropical Capitalists: U.S.-Bound Immigration and Small Enterprise Development in the Dominican Republic", in S. Diaz-Briquets; S. Weintraub (orgs.), Migration, Remittances, and Small Business Development: Mexico and Caribbean Basin Countries. Boulder, CO: Westview Press, 101-131.

Portes, Alejandro; Haller, W.J.; Guarnizo, L.E., (2002), “Transnational Entrepreneurs: An Alternative Form of Immigration Adaptation", American Sociological Review, 67, 278-298. 
Roberts, Bryan R.; Frank, Reanne; Lozano-Asencio, Fernando (1999), “Transnational Migrant Communities and Mexican Migration to the United States", Ethnic and Racial Studies, 22, 238-266.

Smith, Robert C. (1998), "Mexican Immigrants, the Mexican State, and the Transnational Practice of Mexican Politics and Membership”, LASA Forum, 24, 19-24.

Smith, Robert C. (2003a), "Migrant Membership as an Instituted Process: Transnationalization, the State and the Extra-Territorial Conduct of Mexican Politics", International Migration Review, 37(2), 297-343.

Smith, Robert C. (2003b), "Diasporic Memberships in Historical Perspective: Comparative Insights from the Mexican and Italian Cases", International Migration Review, 37(3), 724-59.

Stepick, Alex (1998), Pride against Prejudice: Haitians in the United States. Boston: Allyn and Bacon.

Stepick, Alex et al. (2001), "Shifting Identities and Generational Conflict: Growing up Haitian in Miami", in Ruben G. Rumbaut; Alejandro Portes (orgs.), Ethnicities: Children of Immigrants in America. Berkeley, CA: U. C. Press e Russell Sage Foundation.

Sudman, Seymour (1983), “Applied Sampling”, in Rossi et al. (orgs.), Handbook of Survey Research. New York: Academic Press, 145-194.

Vertovec, Steven (2003), “Migration and Other Modes of Transnationalism”, International Migration Review, 37(3), 641-665. 